\title{
Comparative proteome analysis of Saccharomyces cerevisiae: A global overview of in vivo targets of the yeast activator protein 1
}

\author{
He Jun ${ }^{1,2}$, Thomas Kieselbach ${ }^{1}$ and Leif J. Jönsson ${ }^{1^{*}}$
}

\begin{abstract}
Background: The activity of the yeast activator protein 1 (Yap1p) increases under stress conditions, which leads to enhanced transcription of a number of genes encoding protective enzymes or other proteins. To obtain a global overview of changes in expression of Yap1p-targeted proteins, we compared a Yap1p-overexpressing transformant with a control transformant by triplicate analysis of the proteome using two-dimensional gel electrophoresis (2-DE). Proteins of interest were identified using MALDI-MS or LC-MS/MS.

Results: The relative quantities of 55 proteins were elevated significantly upon overexpression of Yap1p, and most of these proteins were found to have a Yap1p-binding site upstream of their coding sequences. Interestingly, the main metabolic enzymes in the glycolysis and pyruvate-ethanol pathways showed a significant increase in the Yap1p-overexpressing transformant. Moreover, a comparison of our proteome data with transcriptome data from the literature suggested which proteins were regulated at the level of the proteome, and which proteins were regulated at the level of the transcriptome. Eight proteins involved in stress response, including seven heat-shock and chaperone proteins, were significantly more abundant in the Yap1p-overexpressing transformant.

Conclusions: We have investigated the general protein composition in Yap1p-overexpressing S. cerevisiae using proteomic techniques, and quantified the changes in the expression of the potential Yap1p-targeted proteins. Identification of the potential Yap1p targets and analysis of their role in cellular processes not only give a global overview of the ubiquitous cellular changes elicited by Yap1p, but also provide the framework for understanding the mechanisms behind Yap1p-regulated stress response in yeast.
\end{abstract}

Keywords: Yap1, Saccharomyces cerevisiae, Transcription factor, Stress response, Proteome

\section{Background}

The completion of the Saccharomyces cerevisiae genome project and molecular analysis of other fungal species has resulted in the identification of a growing number of yeast AP-1 transcription factors [1]. Characterization of these factors indicates that, like their mammalian counterparts, they activate gene expression in response to a variety of extracellular stimuli [1-4]. The S. cerevisiae transcription factor Yap1p belongs to the bZip (basic domain/leucine zipper) family of transcription factors that includes the yeast Gcn4p and the mammalian activator protein-1 proteins Fos and Jun [2]. Yap1p plays an

\footnotetext{
* Correspondence: leif.jonsson@chem.umu.se

'Department of Chemistry, Umeå University, SE-901 87 Umeå, Sweden

Full list of author information is available at the end of the article
}

important role in oxidative stress response and multidrug resistance by activating target genes encoding protective enzymes or other proteins [4-7]. These observations were corroborated by the analysis of yeast lacking specific Yap1 proteins and by the identification of genes with Yap1p-dependent expression [8-11]. More recently, we found that transcription of the YAP1 gene in yeast was elevated in the presence of coniferyl aldehyde, an inhibitory compound derived from lignocellulose, and that overexpression of Yap1p in S. cerevisiae contributed to enhanced resistance against lignocellulose-derived inhibitory compounds and lignocellulosic hydrolysates [12, 13]. However, the mechanisms behind Yap1p-regulated protective responses are still poorly understood.

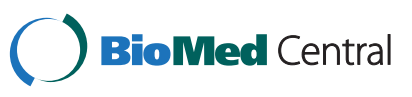

(c) 2012 Jun et al.; licensee BioMed Central Ltd. This is an Open Access article distributed under the terms of the Creative reproduction in any medium, provided the original work is properly cited. 
Yap1p activates transcription by binding to specific DNA sequences located in the promoter of its target genes [1]. Currently, four predicted Yap1p-binding sites (TKACAAA, TGACTAA, TGACTCA, and TTACTAA) have been identified in hundreds of genes [14-16]. Obviously, the Yap1-regulated adaptation to various stimuli strongly depends on the expression of these target genes. To gain insights into how Yap1p regulates the protective response and how the yeast cell adapts to a changing environment, it is very important to get a global overview of changes in expression of these target genes [17].

DNA microarrays provide a practical and economical tool for studying expression of nearly every gene in yeast $[18,19]$. This approach can, in principle, be used to identify all the transcription targets of regulatory proteins like Yap1p. However, accumulating evidence indicates that mRNA abundance does not always correlate well with protein expression levels $[19,20]$. The present study was conducted to explore the changes in expression of Yap1p-targeted proteins at the proteome level. For this purpose, we utilized an S. cerevisiae transformant overexpressing Yap1p and performed triplicate analyses of the proteome by two-dimensional gel electrophoresis (2-DE). Proteins of interest were identified using mass spectrometry (MS). This study provides the mapping of the Yap1p-targeted proteins in S. cerevisiae and offers a global overview of the ubiquitous cellular changes elicited by overexpression of this important yeast transcription factor. To our knowledge this is the first report on the effect of Yap1 overexpression on the yeast proteome.

\section{Results}

\section{Overexpression of Yap1p in S. cerevisiae}

To obtain a global overview of the in vivo Yap1p targets at the proteome level of $S$. cerevisiae, a comparative analysis was performed using a yeast transformant harboring a control plasmid and a transformant with a plasmid carrying the YAP1 gene. Considering the possibility to control $\mathrm{pH}$ and maintain anaerobic conditions, yeast transformants were cultivated in a multi-bioreactor and the fermentation was discontinued when the cells were still in the exponential growth phase. Before 2-DE analysis, overexpression of Yap1p was validated by westernblot analysis. As expected, the Yap1 protein was present at elevated levels in the Yap1p-overexpressing transformant (Figure 1). The level was estimated to be approx. four-fold higher than in the control transformant.

\section{2-DE analyses of protein extracts from $S$. cerevisiae}

Yeast cells from both cultures were harvested and proteins were extracted using the extraction protocol developed by Kolkman et al. [21], which we further optimized for our yeast samples. In the protocol developed by

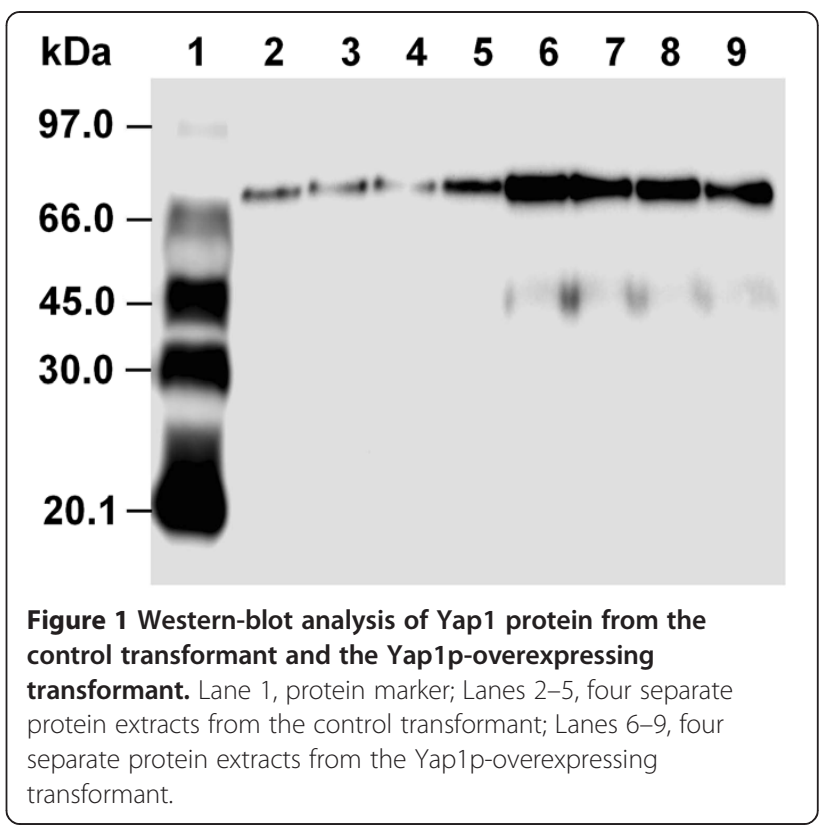

Kolkman et al., the cells are lyophilized and subsequently vortexed with glass beads prior to boiling with SDS. In order to improve cell disruption, we introduced an additional step. Before the SDS boiling, the yeast cells were disrupted in extraction buffer containing thiourea. Cell debris which was not dissolved in the extraction buffer was further exposed to boiling with SDS. More high-molecular-mass proteins $(>70 \mathrm{kDa})$ were observed on the 2-D gels when this optimized extraction protocol was adopted.

In Figure 2, the 2-D gel electrophoresis images of the control transformant (Figure 2A) and the Yap1p-overexpressing transformant (Figure 2B) are shown. By using the SYPRO Ruby staining method, more than 2,000 protein spots were detected on each 2-D gel. This number is higher than what has been achieved by silver staining, for which only a few hundred spots were detected [21]. The 2-DE analyses were performed in triplicate to allow statistical analysis, and Student's $t$-test was used to determine if the relative change in protein expression was statistically significant. Based on this analysis, protein spots that were significantly up-regulated upon Yap1p overexpression were identified on the 2-D gels. In total, 78 such spots were detected on the 2-D gels. Typical examples are shown in Figure $2 \mathrm{C}$ and $\mathrm{D}$. These spots were further analyzed by MALDI-MS and LC-MS/MS, resulting in identification of 55 unique proteins (MALDI-MS was used for most of the protein spots (1-73), while LCMS/MS was used for analysis of a few spots (74-78) for which MALDI-MS analysis did not give satisfactory results). Interestingly, some of the proteins were identified in more than one spot on the 2-D gels. 

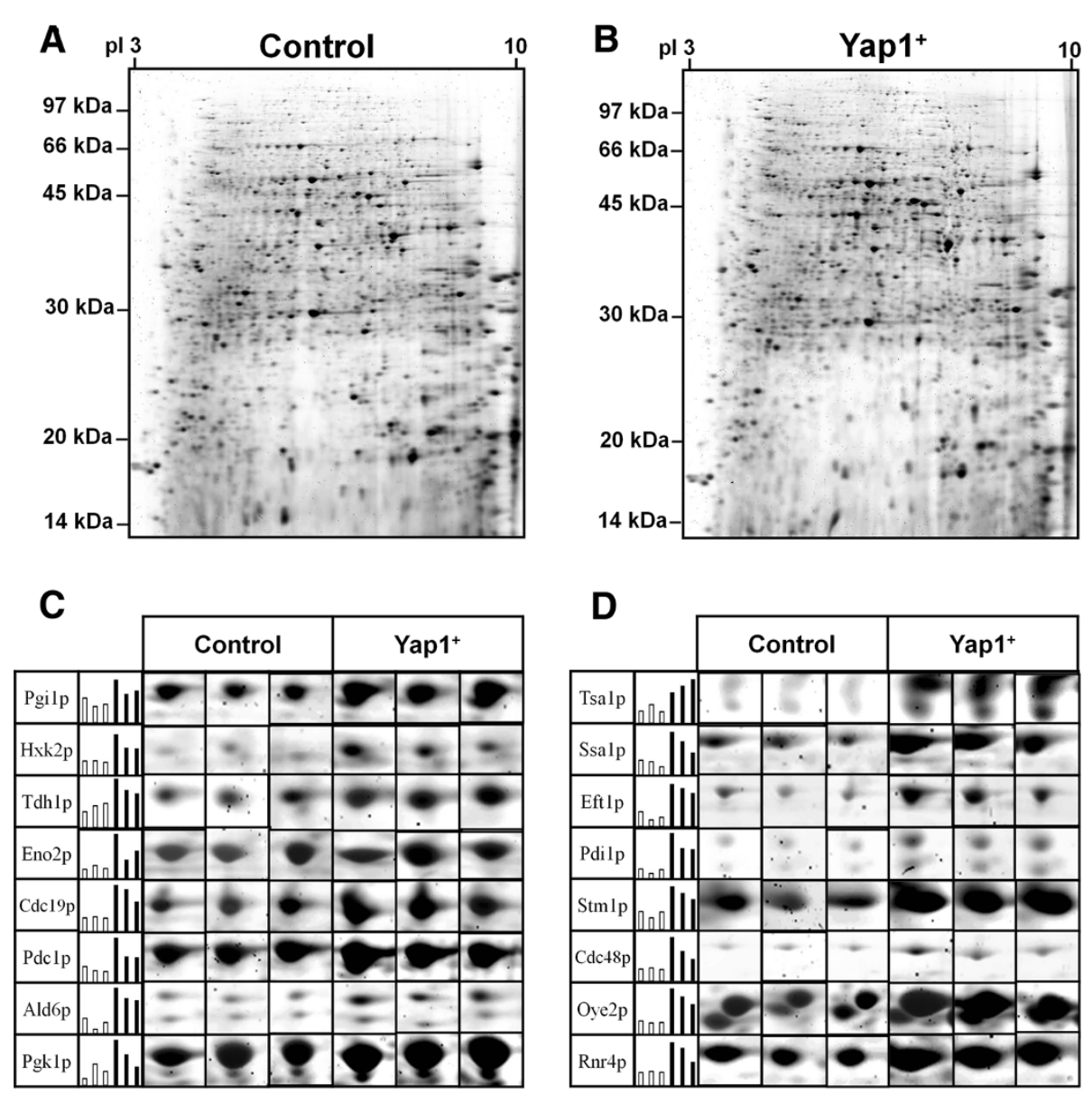

Figure 2 Images of the 2-D gels of protein extracts from yeast cells. The 2-D gels were loaded with $200 \mu \mathrm{g}$ of protein extract from the control transformant (A) or the Yap1p-overexpressing transformant (B). Proteins were visualized by fluorescence staining (Sypro Ruby). Typical data from triplicate 2-D gel images are shown in C (proteins involved in carbon metabolism) and D (proteins involved in pathways other than carbon metabolism). Histograms show the protein abundance, with the spot volume of the 2-D gels indicated in white (control) and black (Yap1p overexpression).

\section{Comparative proteome analysis of S. cerevisiae}

The 55 proteins that were identified are listed in Table 1 and the relative quantity is indicated. Of the averaged total spot volumes of the 55 identified proteins (Table 1), 16 changed significantly at $99 \%$ confidence level $(P<0.01), 33$ changed significantly at the $95 \%$ confidence level $(P<0.05)$, and 6 changed significantly at $90 \%$ confidence level $(P<0.10)$. The identified proteins were divided into different categories, namely enzymes involved in carbon metabolism and proteins involved in pathways other than carbon metabolism, such as protein biosynthesis, cell cycle and growth regulation, etc. (Figure 3A). It is noteworthy that 16 proteins that play a role in carbon metabolism were upregulated in the Yap1p-overexpressing yeast transformant. These proteins include ten glycolytic enzymes (Pgi1p, Hxk2p, Fba1p, Tdh1p, Tdh2p, Tdh3p, Pgk1p, Gpm1p, Eno2p, and Cdc19p), four enzymes involved in conversion of pyruvate to ethanol (Pdc1p, Adh1p, Ald6p, and Dld3p), and two enzymes (Tkl1p and Gnd1p) that are involved in the pentose phosphate pathway. Based on image analysis, we observed that the combined spot volumes of all identified enzymes involved in carbon metabolism enzymes increased about 1.5 fold in the Yap1p-overexpressing transformant (Figure 3B).

Eight proteins involved in stress response were identified that were significantly more abundant in the Yap1poverexpressing transformant. These proteins include seven heat-shock and chaperone proteins (Ssa1p, Ssa2p, Ssb1p, Ssb2p, Hsp82p, Hsc82p, and Sse1p) and one peroxiredoxin (Tsa1p). Compared to the control transformant, most of the heat-shock and chaperone proteins showed more than 2-fold increase in the Yap1p-overexpressing transformant (Table 1). Moreover, 13 proteins involved in protein biosynthesis and 10 proteins involved 
Table 1 Relative changes in protein expression on overexpression of Yap1p. ${ }^{1}$

\begin{tabular}{|c|c|c|c|c|c|c|c|c|}
\hline \multirow[t]{3}{*}{ Protein } & \multirow[t]{3}{*}{ Description } & \multirow[t]{3}{*}{ ORF } & \multicolumn{4}{|c|}{ Normalized averaged spot quantity } & \multirow[t]{3}{*}{$\mathrm{Y} / \mathrm{C}$} & \multirow{3}{*}{$\begin{array}{l}p \text { - } \\
\text { value }\end{array}$} \\
\hline & & & \multicolumn{2}{|c|}{ Control } & \multicolumn{2}{|c|}{ Yap 1 $^{+}$} & & \\
\hline & & & Avol & SD & Avol & SD & & \\
\hline
\end{tabular}

Protein involved in carbon metabolism pathways

\section{Glycolysis}

$\begin{array}{ll}\text { Fba1p } & \text { Fructose-bisphosphate aldolase } \\ \text { Pgi1p } & \text { Glucose-6-phosphate isomerase } \\ \text { Hxk2p } & \text { Hexokinase-2 } \\ \text { Tdh1p } & \text { Glyceraldehyde-3-phosphate dehydrogenase 1 } \\ \text { Tdh2p } & \text { Glyceraldehyde-3-phosphate dehydrogenase 2 } \\ \text { Tdh3p } & \text { Glyceraldehyde-3-phosphate dehydrogenase 3 } \\ \text { Pgk1p } & \text { Phosphoglycerate kinase } \\ \text { Gpm1p } & \text { Phosphoglycerate mutase 1 } \\ \text { Eno2p } & \text { Enolase 2 } \\ \text { Cdc19p } & \text { Pyruvate kinase 1 }\end{array}$

\begin{tabular}{|c|c|c|c|c|c|c|}
\hline YKL060C & 3134 & 89 & 5986 & 1035 & 1.91 & 0.009 \\
\hline YBR196C & 540 & 120 & 950 & 205 & 1.76 & 0.040 \\
\hline YGL253W & 167 & 10 & 374 & 92 & 2.24 & 0.018 \\
\hline YJL052W & 709 & 148 & 1390 & 256 & 1.96 & 0.018 \\
\hline YJR009C & 1769 & 118 & 2516 & 539 & 1.42 & 0.079 \\
\hline YGR192C & 6899 & 401 & 9620 & 195 & 1.39 & $<0.001$ \\
\hline YCR012W & 3970 & 506 & 5204 & 931 & 1.31 & 0.045 \\
\hline YKL152C & 2960 & 508 & 4727 & 284 & 1.60 & 0.006 \\
\hline YHR174W & 11810 & 323 & 15053 & 2147 & 1.27 & 0.041 \\
\hline YAL038W & 1460 & 44 & 3155 & 568 & 2.16 & 0.007 \\
\hline YLR044C & 7914 & 380 & 7443 & 1520 & 1.55 & 0.043 \\
\hline YOL086C & 4200 & 665 & 5158 & 743 & 1.31 & 0.041 \\
\hline YPL061W & 161 & 33 & 329 & 40 & 2.04 & 0.005 \\
\hline YEL071W & 290 & 20 & 501 & 79 & 1.73 & 0.011 \\
\hline YPR074C & 284 & 10 & 619 & 165 & 2.18 & 0.025 \\
\hline YHR183W & 633 & 124 & 876 & 116 & 1.37 & 0.075 \\
\hline
\end{tabular}

\section{Pyruvate branchpoint}

$\begin{array}{ll}\text { Pdc1p } & \text { Pyruvate decarboxylase isozyme } 1 \\ \text { Adh1p } & \text { Alcohol dehydrogenase 1 } \\ \text { Ald6p } & \text { Aldehyde dehydrogenase } \\ \text { Dld3p } & \text { D-lactate dehydrogenase 3 }\end{array}$

\section{Pentose phosphate pathway}

Tkl1p \# Transketolase 1

Gnd1p 6-phosphogluconate dehydrogenase 1

Protein involved in pathways other than carbon metabolism

\section{Amino-acid and nucleotide metabolism}

$\begin{array}{ll}\text { Sah1p } & \text { Adenosylhomocysteinase } \\ \text { Shm } 2 p & \text { Serine hydroxymethyltransferase } \\ \text { Aro9p } & \text { Aromatic amino acid aminotransferase 2 } \\ \text { Lys9p } & \text { Saccharopine dehydrogenase }\end{array}$

\section{Protein biosynthesis}

$\begin{array}{ll}\text { Eft1p } & \text { Elongation factor } 2 \\ \text { Yef3p } & \text { Elongation factor 3A } \\ \text { Gus1p } & \text { Glutamyl-tRNA synthetase } \\ \text { Tef4p } & \text { Elongation factor 1-gamma } 2 \\ \text { Sgt2p } & \text { Small glutamine-rich tetratricopeptide } \\ \text { Rps7ap } & \text { repeat-containing protein } 2 \\ \text { Grs1p } & \text { Glycyl-tRNA synthetase 1 } \\ \text { Kar2p } & 78 \text { kDa glucose-regulated protein } \\ \text { Pdi1p } & \text { Protein disulfide-isomerase } \\ \text { Rpl5p } & 60 \mathrm{~S} \text { ribosomal protein L5 } \\ \text { Rpp0p } & 60 \mathrm{~S} \text { acidic ribosomal protein P0 } \\ \text { Rps3p } & 40 \mathrm{~S} \text { ribosomal protein S3 } \\ \text { Pab1p } & \text { Polyadenylate-binding protein }\end{array}$

\section{Heat-shock and chaperone proteins}

\begin{tabular}{|c|c|c|c|c|c|c|}
\hline YER043C & 631 & 143 & 1310 & 304 & 2.08 & 0.025 \\
\hline YLR058C & 486 & 26 & 944 & 176 & 1.94 & 0.011 \\
\hline YHR137W & 116 & 19 & 164 & 13 & 1.41 & 0.022 \\
\hline YNR050C & 147 & 13 & 364 & 123 & 2.48 & 0.039 \\
\hline YOR133W & 136 & 58 & 456 & 174 & 3.35 & 0.039 \\
\hline YLR249W & 221 & 37 & 378 & 41 & 1.71 & 0.008 \\
\hline YGL245W & 100 & 17 & 254 & 29 & 2.54 & 0.001 \\
\hline YKL081W & 846 & 20 & 1059 & 11 & 1.25 & 0.004 \\
\hline YOR007C & 588 & 67 & 855 & 101 & 1.45 & 0.019 \\
\hline YOR096W & 1377 & 459 & 2742 & 136 & 1.99 & 0.008 \\
\hline YBR121C & 254 & 37 & 361 & 50 & 1.42 & 0.042 \\
\hline YJL034W & 97 & 17 & 303 & 100 & 3.13 & 0.024 \\
\hline YCL043C & 85 & 24 & 354 & 88 & 4.17 & 0.007 \\
\hline YPL131W & 364 & 137 & 1298 & 329 & 3.56 & 0.066 \\
\hline YLR340W & 752 & 88 & 1153 & 161 & 1.53 & 0.019 \\
\hline YNL178W & 342 & 25 & 801 & 214 & 2.34 & 0.095 \\
\hline YER165W & 301 & 52 & 484 & 63 & 1.61 & 0.018 \\
\hline AL005C & 282 & 83 & 792 & 247 & 2.81 & 0.027 \\
\hline
\end{tabular}


Table 1 Relative changes in protein expression on overexpression of Yap1p. ${ }^{1}$ (Continued)

\begin{tabular}{|c|c|c|c|c|c|c|c|c|c|}
\hline Ssa2p ${ }^{\#}$ & Heat shock protein & YLL024C & 1279 & 211 & 2021 & 405 & 1.58 & 0.048 & - \\
\hline Ssb1p ${ }^{\#}$ & Heat shock protein & YDL229W & 258 & 64 & 558 & 141 & 2.16 & 0.028 & + \\
\hline Ssb2p & Heat shock protein & YNL209W & 295 & 72 & 578 & 130 & 1.96 & 0.031 & + \\
\hline Hsp82p & ATP-dependent molecular chaperone & YPL240C & 77 & 17 & 253 & 55 & 3.30 & 0.006 & + \\
\hline Hsc82p ${ }^{\#}$ & ATP-dependent molecular chaperone & YMR186W & 209 & 44 & 487 & 161 & 2.32 & 0.045 & - \\
\hline Sse1p & Heat shock protein homolog & YPL106C & 73 & 16 & 194 & 68 & 2.66 & 0.041 & + \\
\hline \multicolumn{10}{|c|}{ Antioxidants } \\
\hline Tsa1p & Peroxiredoxin TSA1 & YML028W & 656 & 99 & 909 & 90 & 1.39 & 0.031 & + \\
\hline \multicolumn{10}{|c|}{ Respiration } \\
\hline Oye2p $p^{\#}$ & NADPH dehydrogenase 2 & YHR179W & 2129 & 174 & 6677 & 1357 & 3.14 & 0.005 & + \\
\hline Atp2p & ATP synthase subunit beta & YJR121W & 158 & 13 & 313 & 35 & 1.98 & 0.002 & + \\
\hline \multicolumn{10}{|c|}{ Cell cycle and growth regulation } \\
\hline Bfr1p & Nuclear segregation protein & YOR198C & 228 & 79 & 558 & 227 & 2.53 & 0.066 & + \\
\hline Stm1p & Suppressor protein & YLR150W & 2101 & 245 & 3565 & 444 & 1.70 & 0.007 & + \\
\hline Cdc48p $\#$ & Cell division control protein 48 & YDL126C & 121 & 8 & 319 & 110 & 2.65 & 0.036 & + \\
\hline Vma1p & V-type proton ATPase subunit A & YDL185W & 220 & 49 & 318 & 26 & 1.44 & 0.039 & - \\
\hline Vma2p & V-type proton ATPase subunit B & YBR127C & 233 & 99 & 412 & 85 & 1.77 & 0.076 & - \\
\hline Sis1p & Protein SIS1 & YNL007C & 314 & 186 & 702 & 79 & 2.24 & 0.029 & + \\
\hline Rnr4p & Ribonucleoside-diphosphate reductase small chain 2 & YGR180C & 623 & 19 & 1293 & 317 & 2.08 & 0.022 & - \\
\hline $\mathrm{Bg} \mid 2 \mathrm{p}$ & Endo-beta-1,3-glucanase & YGR282C & 580 & 45 & 3453 & 328 & 5.95 & 0.007 & + \\
\hline Bmh1p & Protein BMH1 & YER177W & 1119 & 141 & 1564 & 30 & 1.40 & 0.049 & + \\
\hline Srp1p & Importin subunit alpha & YNL189W & 185 & 24 & 354 & 88 & 1.91 & 0.006 & + \\
\hline \multicolumn{10}{|l|}{ Others } \\
\hline Ola1p & Uncharacterized GTP-binding protein & YBR025C & 281 & 20 & 449 & 79 & 1.59 & 0.024 & + \\
\hline$Y n n 4 p$ & Uncharacterized protein YNL134C & YNL134C & 438 & 176 & 1171 & 354 & 2.67 & 0.033 & + \\
\hline
\end{tabular}

${ }^{1}$ The normalized volume of spots from three replicate 2-D gels was averaged and the standard deviation was calculated for each yeast transformant. A Student's $t$-test was performed to determine if the relative change was statistically significant. If proteins were identified and quantified in more than one spot on the 2-D gels, the total spot volume was calculated (indicated with "\#"). YBS, nucleotide sequence with (+) or without (-) predicted Yap1p-binding site; Avol, averaged value from three spot volumes; $Y / C$, the relative change (Yap1p-overexpression versus control).

in cell cycle and growth regulation were identified on the $2 \mathrm{D}$ gels. The combined spot volumes of all the identified proteins increased about two-fold (Figure 3B).

While the results reported were reproducibly obtained on all 2-D gels analyzed, it should be noted that some spots might have contained co-migrating proteins that were not detected in the MALDI-MS analysis. These proteins would have affected the relative quantification of the up-regulated proteins. As MALDI-MS identifies the prevalent proteins that are present in a gel sample, these errors are, however, considered to be negligible.

\section{Discussion}

The yeast transcription factor Yap1p is crucial for the normal response of yeast cells to a variety of stress conditions including oxidative stress, drug-induced stress, and heat shock $[1,2]$. Previous studies indicated that most stress conditions induced the activity of Yap1p and, as a consequence, resulted in elevated expression of a number of genes encoding proteins that protect the cells against stress-induced damage [4-7]. Although, Yap1p-dependent expression of a diverse range of proteins is essential for viability, a major unresolved question concerns the complete pattern of proteins expressed in a cell upon Yap1p overexpression. We report here the first characterization of the proteome of Yap1p-overexpressing yeast. The experimental approach enables the analysis of the relative protein levels under conditions that mimic stress (Yap1p-overexpression). This resulted in many changes in the levels of proteins involved in crucial biological pathways.

The glycolytic pathway plays a fundamental role in the provision of metabolic energy and intermediates during fermentative growth of the yeast $S$. cerevisiae [22]. The glycolytic enzymes, which are involved in the conversion of glucose to pyruvate, were significantly more abundant 


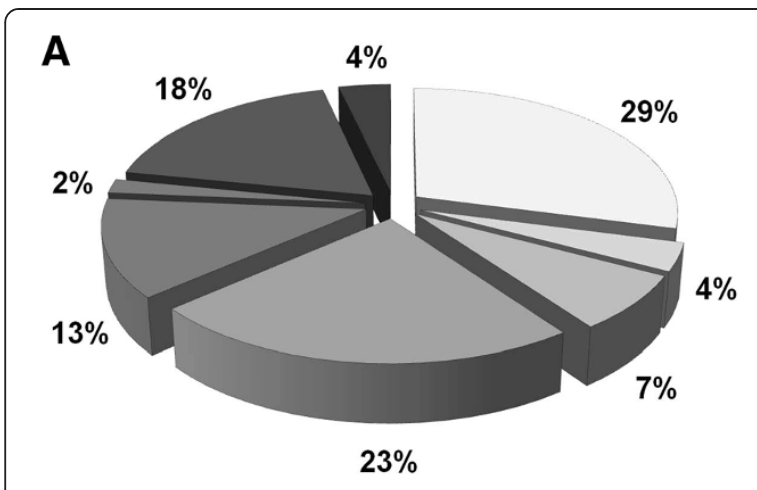

B

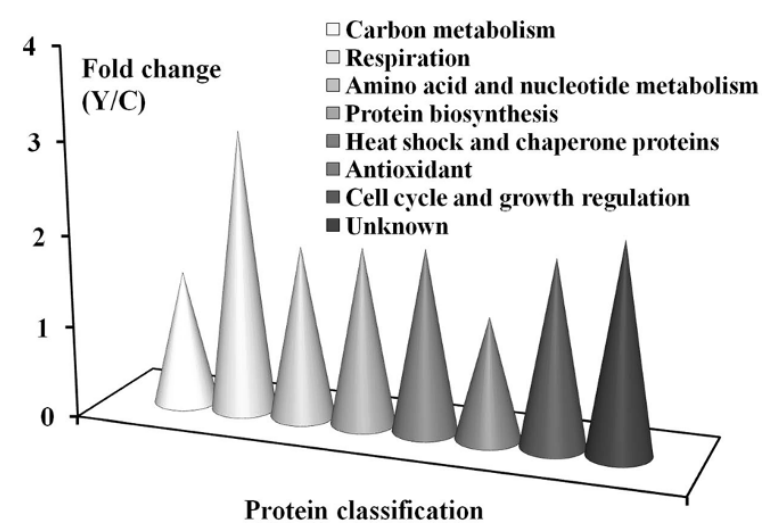

Figure 3 Functional classification of 55 up-regulated proteins in S. cerevisiae upon Yap1p overexpression (A) and fold changes $(\mathrm{Y} / \mathrm{C})$ of combined spot volumes of all identified proteins (B).

in the Yap1p-overexpressing yeast (Figure 4). In particular, the relative abundance of $\mathrm{Hxk} 2 \mathrm{p}$ and $\mathrm{Cdc} 19 \mathrm{p}$ increased more than two-fold. This is most likely due to the fact that they are rate-limiting enzymes in glycolysis [22]. In S. cerevisae, the first irreversible step of glycolysis (phosphorylation of glucose) can be catalyzed by three enzymes, namely the hexokinases Hxk1p and Hxk2p and the glucokinase Glk1p [23]. However, Hxk2p appears to play the main role since it is the predominant isoenzyme during growth on glucose [23, 24]. Moreover, Hxk2p has been identified in the nucleus of the cell and is required for glucose-induced repression of several genes including HXK1 and GLK1 [25, 26]. Our results are consistent with these findings, since Hxk1p and Glk1p were not detected on the 2-D gels. Cdc19p (also known as Pyk1p), which catalyzes the final step of glycolysis, namely the conversion of phosphoenolpyruvate to pyruvate, is the main pyruvate kinase in the glycolysis pathway. In the present study, the relative abundance of Cdc19p increased more than two-fold in the Yap1p- overexpressing yeast. Another isoenzyme, Pyk2p (a second yeast pyruvate kinase), was, however, not detected on the $2 \mathrm{D}$ gels. The regulation mode of pyruvate kinases is similar to that of hexokinases since Cdc19p is tightly regulated and activated by fructose-1,6-bisphophate (FBP), whereas Pyk2p is subject to glucose repression and appears to be insensitive to FBP levels [27].

Relatively few of the identified proteins in the glycolysis and pyruvate-ethanol pathways exhibited more than two-fold increment in the Yap1p-overexpressing yeast. The response suggests that the levels are affected by Yap1p in different ways, and that other factors may also play a role in the regulation. Moreover, none of the enzymes in the citric acid cycle (TCA cycle) were found to be significantly up-regulated upon Yap1p-overexpression. This is probably a result of the anaerobic cultivation conditions. During alcoholic fermentation of sugars, the glycolytic genes are the most efficiently expressed genes in yeast, and glycolytic enzymes comprise over $30 \%$ of the soluble cell protein [28]. Moreover, two crucial enzymes (Pdc1p and Adh1p) involved in the pyruvate-ethanol pathway were significantly up-regulated in the Yap1p-overexpressing yeast, and that would probably result in a shortage of substrate (pyruvate) for the TCA cycle. An alternative mode of glucose oxidation is offered by the pentose phosphate pathway, which provides the cell with pentose sugars and cytosolic NADPH, necessary for biosynthetic reactions, such as the production of fatty acids, amino acids, and sugar alcohols [29]. Importantly, the pathway is also necessary to protect yeast cells against oxidative stress, since NADPH is an essential cofactor for anti-oxidative enzymes [30]. In the present study, two proteins (Tkl1p and Gnd1p) involved in this pathway were identified on the 2-D gels as occurring at higher levels in Yap1p-overexpressing yeast (Table 1).

Overexpression of Yap1p in S. cerevisae resulted in up-regulation of a number of proteins involved in stress response, including seven heat-shock and chaperone proteins (Hsps), and one peroxiredoxin (Table 1). The expression of Hsps is one of the conserved mechanisms of cellular protection [31]. Expression of Hsps was first observed when fruit flies were exposed to high temperatures [32]. However, an elevation of temperature is not the only way to induce the expression of Hsps. Heavy metals, ethanol, oxygen radicals and peroxides are among a large group of agents that can induce Hsps [31-33]. Since stress response also induce the activity of Yap1p [1, 34], our result suggests that Yap1p may be an important activator for Hsps when yeast cells are exposed to stress conditions. The peroxiredoxin Tsa1p was 1.4-fold up-regulated upon overexpression of Yap1p. Tsa1p belongs to a family of thiol-specific peroxidases that catalyze the reduction of peroxides through oxidation of Cys [35]. It has also been 


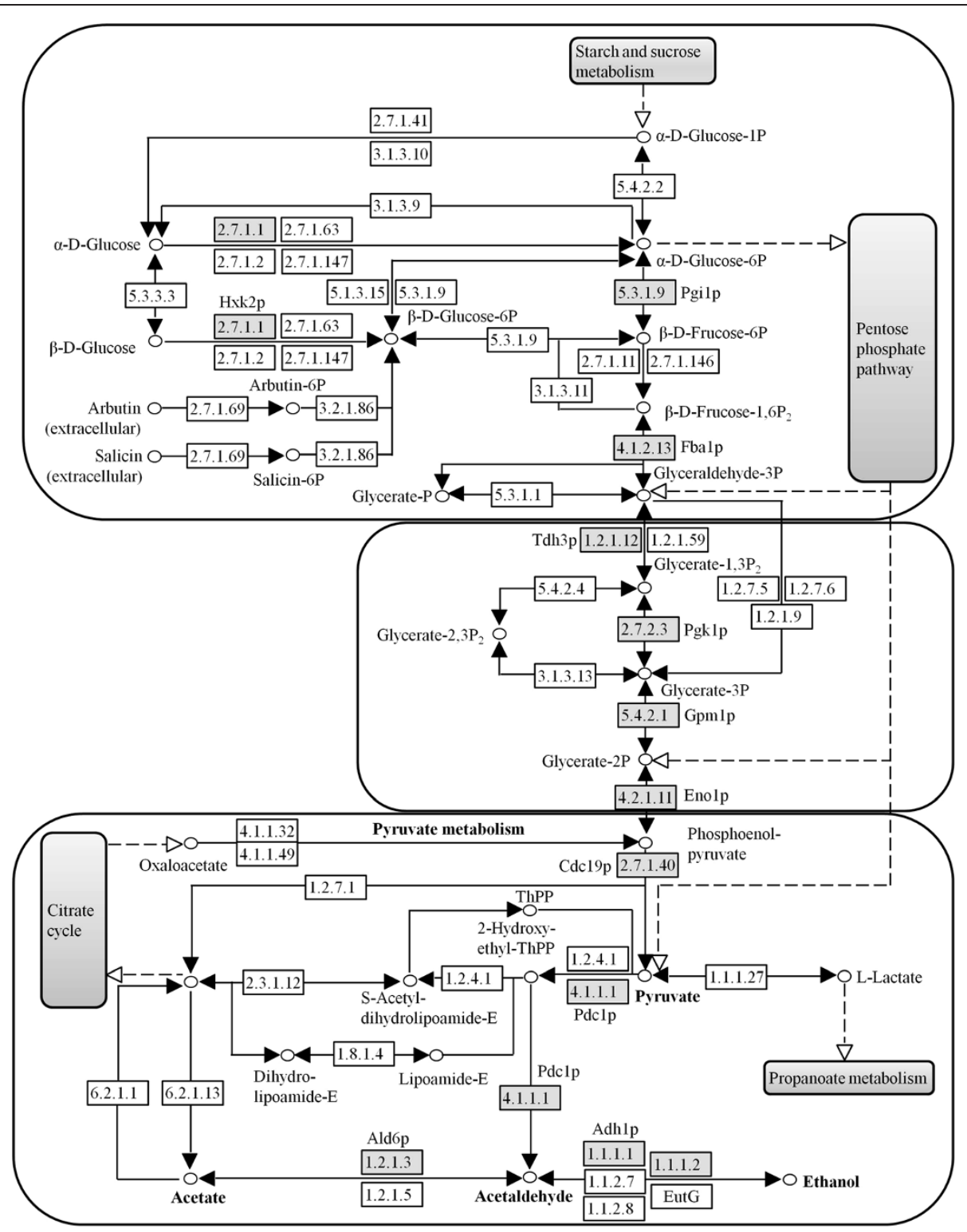

Figure 4 Changes of the glycolysis and pyruvate-ethanol pathways in S. cerevisiae (items selected from http://www.genome.jp/kegg/ pathway.html) upon Yap1p overexpression. Gray boxes indicate up-regulated proteins.

identified as the key peroxidase suppressing genome instability and protecting against cell death in yeast [36]. However, the up-regulation of Tsa1p was relatively modest (Table 1), and the role of Tsa1p in Yap1p-mediated stress response remains elusive. The number of identified antioxidant proteins was rather less than expected, since Yap1p has been described primarily as a central regulator of the response to oxidative stress in S. cerevisiae [5].

A number of proteins involved in cell cycle and growth regulation were identified on the 2-D gels. Interestingly, the protein with the highest absolute increase was the endo-beta-1,3-glucanase (Bgl2p), which is involved in yeast cell wall maintenance [37]. Another significantly up- regulated protein was the cell-division control protein 48 (Cdc48p), which is an abundant and evolutionarily conserved protein involved in many aspects of cellular activities, including homotypic membrane fusion of organelles, ERAD, ubiquitin/proteasome-mediated protein degradation, and cell-cycle control [38-40]. Interestingly, Cdc48p has been observed to participate in the maintenance of the yeast cell wall [41]. Yap1p-mediated up-regulation of Bgl2p and Cdc48p in yeast may be of great importance, since the cell wall gives the cell rigidity and strength, and offers protection against a variety of different forms of stress.

To investigate if the genes encoding these up-regulated proteins are potential transcription targets of Yap1p, we 
have searched upstream of each nucleotide sequence for the predicted Yap1p-binding sites [14-16]. As expected, most genes encoding the identified proteins were found to have a binding site in their promoter region (Table 1). This indicates that most of the up-regulated proteins are transcription targets of Yap1p. However, none of the four predicted binding sites were observed on the coding sequences of proteins such as the glycolytic enzymes Hxk2p, Pgilp and Tdh2p, which suggests that their levels are affected by Yap1p in a different way.

Finally, we compared our proteome data with the literature data for changes of the transcriptome [17]. As shown in Figure 5, most glycolytic enzymes except for Tdh3p and Pgk1p were significantly up-regulated at both the mRNA and the protein level, which suggests that most enzymes in glycolysis are mainly regulated at the transcriptome level. In the pyruvate-to-ethanol pathway, Ald6p is most likely regulated at the level of the proteome, because only the proteome changes were significant, whereas Pdc1p and Adh1p are regulated transcriptionally, as both the mRNA and the protein levels were up-regulated in Yap1p-overexpressing yeast. Although, there are several minor differences between the two studies (i.e. cultivation conditions), it is still noteworthy that mRNA abundance does not always correlate well with protein expression levels. Compared with transcriptome studies, proteome studies are generally limited by the number of gene products that can be analyzed simultaneously [42]. In the present study, the total number of up-regulated targets upon Yap1p-overexpression is less than the number for corresponding transcriptome analysis [17]. Our results, however, not only show that there are some discrepancies between transcriptome and the proteome data, but also indicate

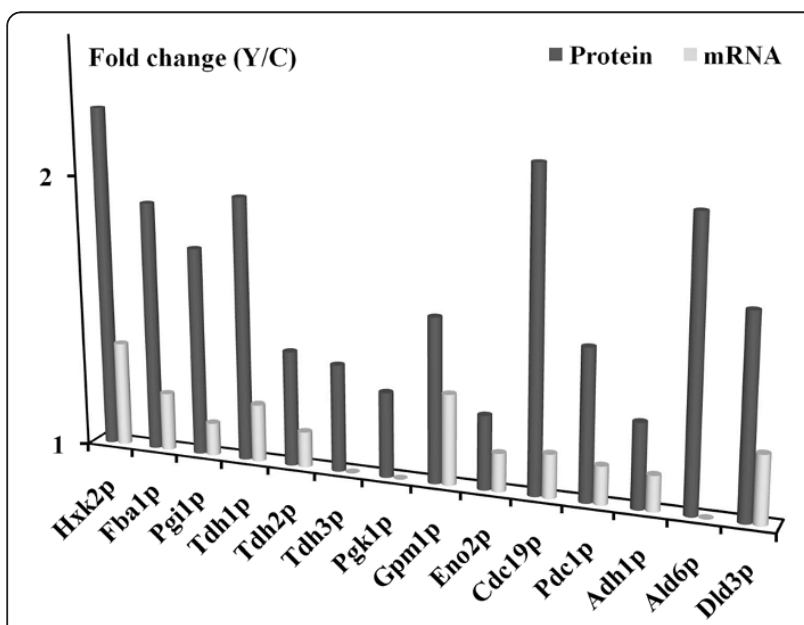

Figure 5 Comparison of the proteome data (this work) and transcriptome data (ref. [17]) for selected proteins involved in the glycolysis and the pyruvate-ethanol pathways. that the combination of the two methodologies can potentially lead to a more complete understanding of the molecular biology of S. cerevisiae.

\section{Conclusions}

We have investigated the general protein composition in Yap1p-overexpressing S. cerevisiae using proteomic techniques, and quantified the changes in the expression of the potential Yap1p-targeted proteins. Mapping the changes in protein expression levels provides insight on how $S$. cerevisiae adapts to a conventional stress condition resulting in activation of Yap1p. Moreover, we were able to elucidate if gene expression in the glycolytic and pyruvate-ethanol pathways are primarily regulated at the level of the proteome or of the transcriptome. Importantly, studies of Yap1p using different experimental conditions may help to further improve our understanding of its effect. Identification of the potential Yap1ptargeted proteins and their mapping into cellular processes not only give a global overview of the ubiquitous cellular changes elicited by Yap1p, but also provide the framework for understanding the mechanisms behind Yap1p-regulated protective response in yeast.

\section{Methods}

\section{Transformants and preparation of inoculums}

All yeast transformants (a Yap1p-overexpressing transformant and a control transformant) that were used in this study were previously constructed and stored in our laboratory [13]. Yeast transformants designated Y (with the YAP1 gene under the control of PGK1 promoter) and $C$ (negative control carrying the same plasmid but without any YAP1 gene) were streaked on SC-Ura agar plates $(20 \mathrm{~g} / \mathrm{l}$ glucose, $6.7 \mathrm{~g} / \mathrm{l}$ yeast nitrogen base without amino acids, $10 \%$ amino-acid supplement solution $\times 10$ excluding uracil, and $20 \mathrm{~g} / \mathrm{l}$ agar) [43], which were then incubated at $30{ }^{\circ} \mathrm{C}$ for $72 \mathrm{~h}$. Inoculum cultures of the two S. cerevisiae transformants were prepared in $500 \mathrm{ml}$ shake flasks with $140 \mathrm{ml}$ of SC-Ura medium (excluding the agar). The flasks were inoculated with cells from the agar plates and incubated for approximately $17 \mathrm{~h}$ at $30^{\circ} \mathrm{C}$ with agitation (Infors Ecotron, Infors AG, Bottmingen, Switzerland). The cells were harvested in the exponential growth phase by centrifugation at $1,200 \times g$ for $10 \mathrm{~min}$ at $4{ }^{\circ} \mathrm{C}$ (Allegra X-22R, Beckman Coulter, Brea, CA, USA). The cells were then resuspended in a suitable amount of sterile $\mathrm{H}_{2} \mathrm{O}$ to yield an inoculum of $0.1 \mathrm{~g} / \mathrm{l}$ (DW) in all bioreactor vessels.

\section{Yeast fermentation in multi-bioreactor}

The cultivation of the two transformants $\mathrm{Y}$ and $\mathrm{C}$ was carried out with a multi-bioreactor system (Sixfors from Infors AG, Bottmingen, Switzerland). Four 350-ml-bioreactor vessels (two vessels per transformant) equipped 
with condensers, FermProbe pH-electrodes (Broadley James Corporation, Irvine, $\mathrm{CA}$ ) and OxyProbe polarographic dissolved-oxygen sensors (pO2-electrodes) (Broadley James Corporation) were sterilized through autoclavation and filled with $250 \mathrm{ml}$ modified SC-Ura medium. The composition of the medium was: $40 \mathrm{~g} / \mathrm{l}$ glucose, $13.4 \mathrm{~g} / \mathrm{l}$ yeast nitrogen base without amino acids, $10 \%$ amino-acid supplement solution $\times 10$ excluding uracil, $0.1 \%$ of an ergosterol/Tween 80 mixture (consisting of $10 \mathrm{~g} / \mathrm{l}$ ergosterol and $420 \mathrm{~g} / \mathrm{l}$ Tween 80 ), and 8 drops of antifoam. ${ }^{12}$ The $\mathrm{pH}$ electrodes and the $\mathrm{pO} 2$ electrodes were calibrated prior to start-up. Two $\mathrm{ml}$ of inoculum were added to each bioreactor vessel to an initial biomass concentration of $0.1 \mathrm{~g} / \mathrm{l}(\mathrm{DW})$. Throughout the fermentation, the temperature was kept at $30{ }^{\circ} \mathrm{C}$, the stirring was kept at $300 \mathrm{rpm}$, and the $\mathrm{pH}$ was kept at 5.5 by automatic addition of $0.5 \mathrm{M} \mathrm{NaOH}$. Nitrogen gas $(15 \mathrm{l} / \mathrm{h})$ was used to maintain anaerobic conditions. The fermentation was discontinued after seven hours when the cells were in the exponential growth phase and had reached a cell density of $1 \mathrm{~g} / \mathrm{l}(\mathrm{DW})$. The yeast cells were harvested by centrifugation at $3,000 \times g$ for $5 \mathrm{~min}$ at $4{ }^{\circ} \mathrm{C}$, and stored at $-80^{\circ} \mathrm{C}$ before protein extraction.

\section{Protein extraction and purification}

Yeast protein extracts were prepared for analysis with 2-DE using a modified approach of Kolkman et al. [21]. In brief, about $100 \mathrm{mg}$ of lyophilized cell pellet were resuspended in $600 \mu \mathrm{l}$ extraction buffer [7 M urea, $2 \mathrm{M}$ thiourea, $4 \%(\mathrm{w} / \mathrm{v})$ CHAPS (3-[(3-cholamidopropyl) dimethylammonio]-1-propanesulfonate), $40 \mathrm{mM}$ dithiothreitol]. Protease inhibitor cocktail (Calbiochem, La Jolla, CA) and glass beads (acid washed, 425-600 $\mu \mathrm{m}$, Sigma-Aldrich, St. Louis, MO) were added to the cell suspension. Cells were disrupted by vortexing six times $60 \mathrm{~s}$ (the samples were cooled on ice for $30 \mathrm{~s}$ in between the vortex steps). The cell extract was transferred to a fresh tube and centrifuged at $20,000 \times g$ for 10 min at $4{ }^{\circ} \mathrm{C}$. The supernatant was transferred completely to a fresh microcentrifuge tube and recovered as Fraction 1. The insoluble fractions were suspended in $400 \mu \mathrm{l}$ SDSbuffer ( $2 \%$ SDS, $40 \mathrm{mM}$ Tris, $60 \mathrm{mM}$ DTT) by thorough vortexing and pipetting up and down with a $200 \mu \mathrm{l}$ pipette tip for 10 times. The sample was boiled for $10 \mathrm{~min}$ and subsequently cooled on ice. After centrifugation for $10 \mathrm{~min}\left(20,000 \times g, 4{ }^{\circ} \mathrm{C}\right)$, the supernatant (Fraction 2) was then transferred to a fresh microcentrifuge tube and mixed with Fraction 1. Subsequently, $75 \mu \mathrm{l}$ of a DNase and RNase solution [1\% (w/v) DNase I, 0.25\% (w/v) RNase A, $50 \mathrm{mM} \mathrm{MgCl}$, $0.5 \mathrm{M}$ Tris-HCl, pH 7.0] were added and the combined fractions were incubated on ice. The mixed protein extract was then purified by using a 2-D Clean-Up Kit (GE Healthcare, Uppsala, Sweden), and the purified protein sample was dissolved in rehydration solution [7 M urea, $2 \mathrm{M}$ thiourea, 4\% (w/v) CHAPS, 0.002\% (w/v) bromophenol blue] supplemented with $2 \%(\mathrm{v} / \mathrm{v}) 3-$ $10 \mathrm{NL}$ IPG buffer (GE Healthcare) and $5.4 \mathrm{mg} / \mathrm{ml}$ dithiothreitol. Total protein concentration was determined using the 2-D Quant Kit (GE Healthcare). Aliquots of extracellular protein samples were stored at $-80^{\circ} \mathrm{C}$ before proteomic assays.

The peaklist files of the processed mass spectra of spots 1 to 78 are provided in the appendix. Additional file 1: Spots 1 to 73 were analysed by MALDI-TOF-MS and the peaklist files are available in the supplementary zip files: Additional file 2: 1-5_MALDI_MS_data, Additional file 3: 6-10_MAL DI_MS_data, Additional file 4: 11-15_MALDI_MS_data, Additional file 5: 16-20_MALDI_MS_data, Additional file 6: 21-25_MALDI_MS_data, Additional file 7: 26-30_MAL DI_MS_data, Additional file 8: 31-35_MALDI_MS_data, Additional file 9: 36-40_MALDI_MS_data, Additional file 10: 41-45_MALDI_MS_data, Additional file 11: 4650_MALDI_MS_data, Additional file 12: 51-55_MAL DI_MS_data, Additional file 13: 56-60_MALDI_MS data, Additional file 14: 61-65_MALDI_MS_data, Additional file 15: 66-69_MALDI_MS_data,_and Additional file 16: 70-73_MALDI_MS_data. As for spots 74 to 78 , analysis was performed by LC-MS/MS and the corresponding mzML files are provided in the supplementary zip files Additional file 17: 74_LC_MS MS_data, Additional file 18: 75_LC_MS_MS_data, Additional file 19: 76_LC_MS_MS_data, Additional file 20: 77_LC_MS_MS_data, and Additional file 21: 78_LC_MS_MS_data.

\section{Western-blot analysis of Yap1 protein}

The crude protein extracts were separated by SDSPAGE after adding $5 \times$ Laemmli sample buffer and boiling. The separated proteins were transferred onto a PVDF membrane by semi-dry blotting and probed (1:2000 dilution, incubated overnight at $4{ }^{\circ} \mathrm{C}$ ) with a rabbit polyclonal antibody directed against amino-acid residues 351-650 at the C-terminus of $S$. cerevisiae Yap1p (Santa Cruz Biotechnology, Santa Cruz, CA). Goat anti-rabbit IgG-HRP (Santa Cruz Biotechnology) was used as secondary antibody. Bound antibodies were detected by the ECL Prime western blotting detection reagent (GE Healthcare) using a CCD-based imager (ImageQuant LAS 4000, GE Healthcare).

\section{2-D gel electrophoresis}

For the first dimension (IEF), an amount of $200 \mu \mathrm{g}$ of protein $(300 \mu \mathrm{l})$ prepared as described in section Protein Extraction and Purification was loaded on a $13 \mathrm{~cm}$ Immobiline Dry-Strip pH 3-10 NL (GE Healthcare), and the IPG strips were rehydrated overnight at room temperature. Isoelectric focusing (IEF) was performed with a Multiphor II system (GE Healthcare) at $20{ }^{\circ} \mathrm{C}$ with a 3-phase gradient program: $500 \mathrm{~V}$ for $0.25 \mathrm{kVh}$, 
$3500 \mathrm{~V}$ for $5.25 \mathrm{kVh}$, and $3500 \mathrm{~V}$ for $45 \mathrm{kVh}$. Prior to the second dimension (SDS-PAGE), the IPG strips were incubated for $15 \mathrm{~min}$ in equilibration buffer [50 mM Tris- $\mathrm{HCl}, 6 \mathrm{M}$ urea, 30\% (v/v) glycerol, 2\% $(\mathrm{w} / \mathrm{v})$ SDS, $0.002 \%(\mathrm{w} / \mathrm{v})$ bromophenol blue] containing $1 \%(\mathrm{w} / \mathrm{v})$ dithiothreitol, followed by $15 \mathrm{~min}$ incubation in equilibration buffer containing $2.5 \%(\mathrm{w} / \mathrm{v})$ iodoacetamide. Second-dimension electrophoresis was performed on PROTEIN ${ }^{\mathrm{TM}}$ II electrophoresis system (Bio-Rad, Hercules, CA). The IPG strips were placed on top of $12.5 \%$ polyacrylamide gels and sealed with a solution of $1 \%(\mathrm{w} / \mathrm{v})$ agarose containing a trace of bromophenol blue. The vertical gels were run at $10 \mathrm{~mA}$ per gel for $30 \mathrm{~min}$ followed by $25 \mathrm{~mA}$ per gel until the bromophenol blue had migrated to the bottom of the gel. The temperature was maintained at $15{ }^{\circ} \mathrm{C}$ using MultiTemp III system (GE Healthcare). Proteins were visualized using SYPRO Ruby Protein Gel Stain (Invitrogen, Carlsbad, CA). The SYPRO Ruby-stained gels were scanned at $532 \mathrm{~nm}$ using a Typhoon 9400 scanner (GE Healthcare).

\section{Experimental design, image analysis, and statistics}

For each transformant, namely Yap1p-overexpressing transformant and control transformant, 2-D gels were run in triplicate. Additionally, a master 2-D gel was prepared, which contained a 1:1 mixture of the protein extract from the two yeast transformants. That gel, which should contain all protein spots present on the 2-D gels with samples from the Yap1p-overexpressing and the control transformant, was used during image analysis as a master gel. Image analysis was performed using the ImageMaster II software (GE Healthcare). The quantitative and statistical analyses were performed using suitable functions within the ImageMaster II software and Excel software (Microsoft, Redmond, WA). The normalized intensity of spots on three replicate 2-D gels was averaged and the standard deviation was calculated. The relative change in protein abundance for the Yap1p-overexpressing transformant $(\mathrm{Y})$ versus the control transformant $(\mathrm{C})$ (indicated with "fold change $\mathrm{Y} / \mathrm{C}$ ") for each protein spot was calculated by dividing the averaged spot quantity from gels with samples from the Yap1p-overexpressing transformant by the averaged spot quantity from gels with samples from the control transformant. A two-tailed non-paired Student's $t$-test was performed to determine if the relative change was statistically significant.

\section{In-gel tryptic digestion}

Protein spots of interest were picked from the 2-D gels using an Ettan Spotpicking Station (GE Healthcare) and destained three times using a fresh solution of $20 \mathrm{mM}$ ammonium bicarbonate containing 35\% (v/v) acetonitrile $(\mathrm{ACN})$. Subsequently, the gel pieces were dried by two washes using 100\% neat acetonitrile and re-hydrated on ice using a solution of sequencing grade modified trypsin (Promega, Madison, WI) in $20 \mathrm{mM}$ ammonium bicarbonate. The trypsin concentration depended on the intensity of the spots and was 2 to $3 \mathrm{ng} / \mu \mathrm{l}$. The rehydrated gel samples were incubated in $37{ }^{\circ} \mathrm{C}$ for overnight digestion and either analyzed immediately or stored at $-20{ }^{\circ} \mathrm{C}$ until further analysis.

\section{Mass spectrometry}

MALDI-MS spectra for peptides were acquired using a Voyager DE-STR mass spectrometer (AB SCIEX, Framingham, MA, USA) as described by Yao et al. [44]. LC-MS/MS combined with ESI-ion-trap MS was performed using an HCT-Ultra ETD II mass spectrometer from Bruker (Bremen, Germany) linked to an Easy-nLC system from Proxeon (Odense, Denmark). Spectra were acquired using the enhanced scanning mode covering a mass range from $\mathrm{m} / \mathrm{z}$ 350 to $\mathrm{m} / z$ 1300. The LC separation of peptides was performed using a $5 \mu \mathrm{m}$ C18 column $(375 \mu \mathrm{m}$ OD/75 $\mu \mathrm{m}$ ID $\times$ $10 \mathrm{~cm}$ ) from NanoSeparations (Nieuwkoop, The Netherlands) and a 30 min gradient ranging from 0 to 60 percent of acetonitrile. The flow rate was $300 \mathrm{nl} \mathrm{min}^{-1}$. Data processing was performed using the Data Analysis software (4.0 SP4) (Bruker, Bremen, Germany) using default setting for processing and AutoMSn detection of compounds.

\section{Protein identification}

Database searches using the peak list files (mgf-format) of the processed mass spectra were performed using an in-house license of Mascot (www.matrixscience.com), and searches were performed using the Swiss-Prot or NCBInr database. As for MALDI-MS spectra, a mass error of $50 \mathrm{ppm}$ and one missed cleavage sites were permitted. In addition, variable modifications allowed included methionine oxidation and carbamidomethylation of cysteine residues. As for LC-MS/MS data a mass error of 0.3 Da was allowed for both the MS and MS/ MS mode and variable modifications were set as for the database searches with the MALDI-MS data.

\section{Additional files}

\footnotetext{
Additional file 1 Spots 1 to 78 .

Additional file 2 1-5_MALDI_MS.

Additional file 3 6-10_MALDI_MS.

Additional file 4 11-15_MALDI_MS.

Additional file 5 16-20_MALDI_MS.

Additional file 6 21-25_MALDI_MS.

Additional file 7 26-30_MALDI_MS.

Additional file 8 31-35_MALDI_MS.

Additional file 9 36-40_MALDI_MS.

Additional file 10 41-45_MALDI_MS.

Additional file 11 46-50_MALDI_MS.
} 


\section{Additional file 12 51-55_MALDI_MS. \\ Additional file 13 56-60_MALDI_MS. \\ Additional file 14 61-65_MALDI_MS. \\ Additional file 15 66-69_MALDI_MS. \\ Additional file 16 70-73_MALDI_MS. \\ Additional file 17 74_LC_MS_MS. \\ Additional file 18 75_LC_MS_MS. \\ Additional file 19 76_LC_MS_MS. \\ Additional file 20 77_LC_MS_MS. \\ Additional file 21 78_LC_MS_MS.}

\section{Competing interests}

The authors declare that they have no competing interests.

\section{Authors' contributions}

$\mathrm{HJ}$ carried out the cultivation of the yeast, the sample preparation and the 2-DE analyses, and drafted the manuscript. TK carried out in-gel digestions and massspectrometric analyses. $\sqcup J$ J conceived and organized the study and helped to draft the manuscript. All authors read and approved the final manuscript.

\section{Acknowledgements}

We thank Dr. Björn Alriksson for help with the cultivation of yeast cells. This work was supported by the Kempe Foundations, the Knut and Alice Wallenberg Foundation, the Bio4Energy program (www.bio4energy.se), the Carl Trygger Foundation (TK) and the Swedish Research Council (822-2007-3473).

\section{Author details}

'Department of Chemistry, Umeå University, SE-901 87, Umeå, Sweden. ${ }^{2}$ Research Institute of Animal Nutrition, Sichuan Agricultural University, Ya'an, Sichuan 625014, People's Republic of China.

Received: 15 December 2011 Accepted: 3 April 2012

Published: 9 June 2012

\section{References}

1. Toone WM, Jones N: AP-1 transcription factors in yeast. Curr Opin Genet Dev 1999, 9:55-61.

2. Moye-Rowley WS, Harshman KD, Parker CS: Yeast Yap1 encodes a novel form of the jun family of transcriptional activator proteins. Genes Dev 1989, 3:283-292.

3. Gulshan K, Lee SS, Moye-Rowley WS: Differential oxidant tolerance determined by the key transcription factor Yap1 is controlled by levels of the Yap1-binding protein, Ybp1. J Biol Chem 2011, 286:34071-34081.

4. Schnell N, Krems B, Entian KD: The PAR1 (YAP1/SNQ3) gene of Saccharomyces cerevisiae, a c-jun homologue, is involved in oxygen metabolism. Curr Genet 1992, 21:269-273.

5. Kuge $\mathrm{S}$, Jones N, Nomoto A: Regulation of yAP-1 nuclear localization in response to oxidative stress. EMBO J 1997, 16:1710-1720.

6. Grant CM, Collinson LP, Roe JH, Dawes IW: Yeast glutathione reductase is required for protection against oxidative stress and is a target for yAP-1 transcriptional regulation. Mol Microbiol 1996, 21:171-179.

7. Wu A, Moye-Rowley WS: GSH1, which encodes $\gamma$-glutamylcysteine synthetase, is a target gene for yAP-1 transcriptional regulation. Mol Cell Biol 1994, 14:5832-5839.

8. Hertle K, Haase E, Brendel M: The SNQ3 gene of Saccharomyces cerevisiae confers hyper-resistance to several functionally unrelated chemicals. Curr Genet 1991, 19:1-4.

9. Schnell N, Entian KD: Identification and characterization of a Saccharomyces cerevisiae gene (PAR1) conferring resistance to iron chelators. Eur J Biochem 1991, 200:487-493.

10. Teixeira MC, Dias PJ, Simoes T, Sa-Correia I: Yeast adaptation to mancozeb involves the up-regulation of FLR1 under the coordinate control of Yap1, Rpn4, Pdr3, and Yrr1. Biochem Bioph Res Commun 2008, 367:249-255.

11. Turton HE, Dawes IW, Grant CM: Saccharomyces cerevisiae exhibits a yAP-1 mediated adaptive response to malondialdehyde. J Bacterio/ 1997 179:1096-1101.
12. Sundström L, Larsson S, Jönsson LJ: Identification of Saccharomyces cerevisiae genes involved in the resistance to phenolic fermentation inhibitors. App/ Biochem Biotechnol 2010, 161:106-115.

13. Alriksson B, Horvath HS, Jönsson LJ: Overexpression of Saccharomyces cerevisiae transcription factor and multidrug resistance genes conveys enhanced resistance to lignocellulosesderived fermentation inhibitors. Process Biochem 2010, 45:264-271.

14. Fernandes $L$, Rodrigues-Pousada C, Struhl K: Yap, a novel family of eight bZIP proteins in Saccharomyces cerevisiae with distinct biological functions. Mol Cell Biol 1997, 17:6982-6993.

15. Nguyen DT, Alarco AM, Raymond M: Multiple Yap1p-binding sites mediate induction of the yeast major facilitator FLR1 gene in response to drugs, oxidants, and alkylating agents. J Biol Chem 2001, 276:11381145 .

16. He XJ, Fassler JS: Identification of novel Yap1p and Skn7p binding sites involved in the oxidative stress response of Saccharomyces cerevisiae. Mol Microbiol 2005, 58:1454-1467.

17. DeRisi JL, Lyer VR, Brown PO: Exploring the metabolic and genetic control of gene expression on a genomic scale. Science 1997, 278:680-686

18. Schema M, Shalon D, Davis RW, Brown PO: Quantitative monitoring of gene expression patterns with a complementary DNA microarray. Science 1995, 270:467-470.

19. Ideker T, Thorsson V, Ranish JA, Christmas R, Buhler J, Eng JK, Bumgarner R, Goodlett DR, Aebersold R, Hood L: Integrated genomic and proteomic analyses of a systematically perturbed metabolic network. Science 2001, 292:929-934.

20. Criffin TJ, Gygi SP, Ideker T, Rist B, Eng J, Hood L, Aebersold R: Complementary profiling of gene expression at the transcriptome and proteome levels in Saccharomyces cerevisiae. Mol Cell Proteomics 2002, 1:323-333.

21. Kolkman A, Olsthoorn MMA, Heeremans CEM, Heck AJR, Slijper M: Comparative proteome analysis of Saccharomyces cerevisiae grown in chemostat cultures limited for glucose or ethanol. Mol Cell Proteomics 2005, 4:1-11.

22. Nelson DL, Cox MM: Lehninger Principles of Biochemistry. 4th edition. New York: Freeman; 2004:527.

23. Bianconi ML: Calorimetric determination of thermodynamic parameters of reaction reveals different enthalpic compensations of the yeast hexokinase isozymes. J Biol Chem 2003, 278: 18709-18713.

24. Walsh RB, Kawasaki G, Fraenkel DG: Cloning of genes that complement yeast kexokinase and glucokinase mutants. J Bacteriol 1983, 154:1002-1004.

25. Gancedo JM: Yeast carbon catabolite repression. Microbiol Mol Biol Rev 1998, 62:334-361.

26. Rodriquez A, De La Gera T, Herrero P, Moreno F: The hexokinase 2 protein regulates the expression of the GLK1, HXK1 and HXK2 genes of Saccharomyces cerevisiae. Biochem J 2001, 355:625-631.

27. Boles E, Schulte F, Miosqa T, Freidel K, Schluter E, Zimmermann FK, Hollenberg CP, Heinishch JJ: Characterization of a glucose-repressed pyruvate kinase (Pyk2p) in Saccharomyces cerevisiae that is catalytically insensitive to fructose-1, 6-bisphosphate. J Bacteriol 1997, 179:2987-2993.

28. Wills C: Regulation of sugar and ethanol metabolism in Saccharomyces cerevisiae. Crit Rev Biochem Mol Biol 1990, 25:245-280.

29. Kruger NJ, von Schaewen A: The oxidative pentose phosphate pathway: structure and organization. Curr Opin Plant Biol 2003, 6:236-246.

30. Juhnke $H$, Krems B, Kotter P, Entian KD: Mutants that show increased sensitivity to hydrogen peroxide reveal an important role for the pentose-phosphate pathway in protection of yeast against oxidative stress. Mol Gen Genet 1996, 252:456-464.

31. De Maio A: Heat shock proteins: facts, thoughts, and dreams. Shock 1999, 11:1-12.

32. Lindquist S, Craig EA: The heat-shock proteins. Annu Rev Genet 1988 , 22:316-377

33. Minowada $G$, Welch WJ: Clinical implications of the stress response. J Clin Invest 1995, 95:3-12.

34. Hirata D, Yano K, Miyakawa T: Stress-induced transcriptional activation mediated YAP1 and YAP2 genes that encode the Jun 
family of transcriptional activators in Saccharomyces cerevisiae. Mol Gen Genet 1994, 242:250-256.

35. Rhee SG, Chae HZ, Kim K: Peroxiredoxins: a historical overview and speculative preview of novel mechanisms and emerging concepts in cell signaling. Free Radic Biol Med 2005, 38:1543-1552.

36. Iraqui I, Kienda G, Soeur J, Faye G, Baldacci G, Kolodner RD, Huang ME: Peroxiredoxin Tsa1 is the key peroxidase suppressing genome instability and protecting against cell death in Saccharomyces cerevisiae. PLoS One 2009, 5:e1000524.

37. Mrsa V, Klebl F, Tanner W: Purification and characterization of the Saccharomyces cerevisiae BGL2 gene product, a cell wall endo- $\beta-1,3-$ glucanase. J Bacteriol 1993, 175:2102-2106.

38. Latterich M, Frohlich KU, Schekman R: Membrane fusion and the cell cycle: Cdc48p participates in the fusion of ER membranes. Cell 1995, 82:885-893.

39. Bar-Nun S: The role of $p 97 / C d c 48 p$ in endoplasmic reticulum-associated degradation: from the immune system to yeast. Curr Top Microbiol Immunol 2005, 300:95-125.

40. Rumpf S, Jentsch S: Functional division of substrate processing cofactors of the ubiquitin-selective Cdc48 chaperone. Mol Cell 2006, 21:261-269.

41. Hsieh MT, Chen RH: Cdc48 and cofactors Npi4-Ufd1 are important for G1 progression during heat stress by maintaining cell wall integrity in Saccharomyces cerevisiae. PLoS One 2011, 6:e18988.

42. Kolkman A, Slijper M, Heck AJR: Development and application of proteomics technologies in Saccharomyces cerevisiae. Trends Biotechnol 2005, 23:598-604.

43. Sambrook J, Russel DW: Molecular Cloning- A Laboratory Manual. 3rd edition. New York: Cold Spring Harbor Laboratory Press; 2001:418.

44. Yao D, Kieselbach T, Komenda J, Promnares K, Prieto MA, Tichy M, Vermaas W, Funk C: Localization of the small CAB-like proteins in photosystem II. J Biol Chem 2007, 282:267-276.

doi:10.1186/1471-2164-13-230

Cite this article as: Jun et al: Comparative proteome analysis of Saccharomyces cerevisiae: A global overview of in vivo targets of the yeast activator protein 1. BMC Genomics 2012 13:230.

\section{Submit your next manuscript to BioMed Central and take full advantage of:}

- Convenient online submission

- Thorough peer review

- No space constraints or color figure charges

- Immediate publication on acceptance

- Inclusion in PubMed, CAS, Scopus and Google Scholar

- Research which is freely available for redistribution 